\title{
Minimal dose of milk protein concentrate to enhance the anabolic signalling response to a single bout of resistance exercise; a randomised controlled trial
}

Cameron J. Mitchell ${ }^{1 *}$, Nina Zeng ${ }^{1}$, Randall F. D'Souza ${ }^{1}$, Sarah M. Mitchell ${ }^{1}$, Kirsten Aasen ${ }^{1}$, Aaron C. Fanning ${ }^{3}$, Sally D. Poppitt ${ }^{2}$ and David Cameron-Smith ${ }^{1}$

\begin{abstract}
Background: Resistance training is a potent stimulus to induce muscle hypertrophy. Supplemental protein intake is known to enhance gains in muscle mass through activation of the mammalian target of rapamycin complex 1 (mTORC1) pathway, which initiates protein translation. While the optimal dose of high quality protein to promote post exercise anabolism in young or older men has been investigated, little is known about the minimum doses of protein required to potentiate the resistance exercise activation of anabolic signalling in middle aged men.

Methods: Twenty healthy men ( $46.3 \pm 5.7$ years, BMl: $\left.23.9 \pm 6.6 \mathrm{~kg} / \mathrm{m}^{2}\right)$ completed a single bout of unilateral resistance exercise consisting of 4 sets of leg extension and press at $80 \%$ of 1 repetition maximum. Participants were randomised to consume either formulated milk product containing $9 \mathrm{~g}$ milk protein (FMP) or an isoenergetic carbohydrate placebo $(\mathrm{CHO})$ immediately post exercise, in a double blind fashion. A single muscle biopsy was collected at pre-exercise baseline and then bilateral biopsies were collected 90 and 240 min after beverage consumption.

Results: P70S6K ${ }^{\text {Thr389 }}$ phosphorylation was increased with exercise irrespective of group, P70S6K $K^{\text {Thr } 421 / S e r 424}$ was increased with exercise only in the FMP group at 240 min. Likewise, rpS6 ${ }^{\text {Ser235/236 }}$ phosphorylation was increased with exercise irrespective of group, rpS6 ${ }^{\text {Ser240/244 }}$ increased to a greater extent following exercise in the FMP group. mRNA expression of the amino acid transporter, LAT1/ SLC7A5 increased with both exercise and beverage consumption irrespective of group. PAT1/ SLC36A1, CAT1/ SLC7A1 and SNAT2/ SLC38A2 mRNA increased only after exercise regardless of group.

Conclusions: Nine grams of milk protein is sufficient to augment some measures of downstream mTORC1 signalling after resistance exercise but does not potentiate exercise induced increases in amino acid transporter expression. Formulated products containing nine grams of milk protein would be expected stimulate muscle anabolism after resistance exercise.
\end{abstract}

Trial registration: New Zealand Clinical Trials Registry ACTRN12615001375549. Registered: 17 December, 2015. Keywords: Skeletal muscle, Middle age, P70SK, Supplement, Protein phosphorylation

\footnotetext{
* Correspondence: cameron.mitchell@auckland.ac.nz

${ }^{1}$ Liggins Institute, The University of Auckland, Private Bag 92 019, Victoria

Street West, Auckland 1142, New Zealand

Full list of author information is available at the end of the article
} 


\section{Background}

Skeletal muscle mass and function are key determinants of both metabolic health [1] and physical performance $[2,3]$. Importantly for an ageing population, muscle mass and function is reduced with increasing age, impairing whole body insulin sensitivity [1] and mobility [4]. There is a measurable decline in muscle mass commencing from around the fourth decade of life [5], hence middle age is an obvious target for interventions to preserve muscle mass. Yet despite this, few studies have examined effective strategies for this demographic.

While resistance training can increase muscle mass and strength in both young and older adults [6], the relative magnitude of these gains decrease with age [79]. Post-exercise protein intake has been shown to augment resistance training induced muscle mass gains [10]. In older adults greater protein doses are required to maximally stimulate muscle protein synthesis (MPS) [11] and the necessary anabolic signalling within muscles [12]. Yet despite the importance of establishing a maximal effective dose, it is also necessary to establish the efficacy of smaller protein doses, including those that are typically incorporated into a range of consumer goods. The addition of large amounts of protein to mass market products can increase the cost to the consumer, alter taste [13] and limit formulation options [14]. Thus many foods consumed after resistance exercise may include a suboptimal protein dose.

Muscle mass is regulated by both anabolic and catabolic processes [15]. Following resistance exercise and protein ingestion, there is a much greater magnitude increase in anabolic processes compared to the suppression of catabolism [16], thus anabolic processes are thought to exert a primary regulatory role in dictating muscle mass gains $[17,18]$. The increase in MPS in response to both exercise and feeding is driven by the initiation of protein translation [19]. This occurs via the pathway centred on the mammalian target of rapamycin complex 1 (mTORC1), which integrates signals from growth factors, mechanical stimuli, cellular energy status and amino acids. Once activated, mTORC1 phosphorylates a number of downstream effectors including P70S6 kinase (P70S6K) and ribosomal protein S6 (rpS6) which subsequently enable the initiation of protein translation [20]. Studies have correlated the activation of these kinases with both acute increases in MPS [21] and long term gains in muscle size [22, 23].

Previously it has been demonstrated that high dose milk protein concentrate (MPC) consumption results in an equivalent anabolic response to a matched dose of whey protein, in middle-aged men at rest [24]. Further studies from our group have also shown that as little as $10 \mathrm{~g}$ dose of MPC is sufficient to stimulate MPS with no effect on downstream anabolic signalling in this group
[25]. Thus, the purpose of the present study was to determine if a similar quantity of milk protein would augment the anabolic signalling response downstream of mTORC1, to a single bout of resistance exercise in middle-aged men. Further analyses were undertaken to characterize the transcriptional response of skeletal muscle amino acids transporters LAT1/ SLC7A5, PAT1/, SLC36A1, CAT1/ SLC7A1 and SNAT2/ SLC38A2 which have been shown to increase in response to resistance exercise [26] and large doses of essential amino acids [27].

\section{Methods \\ Participants}

Twenty men between the ages of 38 and 55 years participated in the study. The men were not taking any medication and had no neuromuscular, metabolic or cardiovascular medical conditions. Participants were sedentary to recreationally active, but did not participate in resistance training. Baseline characteristics are shown in Table 1. All participants provided informed verbal and written consent, the study was approved by the Health and Disability Ethics Committee (New Zealand, Ref\# 15/ NTB/154/AM01) and registered with the Australia New Zealand Clinical Trials Registry ACTRN12615001375549.

\section{Study beverages}

Using a parallel double blind design, participants were randomized to consume one of two study beverages, using sequences generated with www.random.org. Beverages were Functional milk product (FMP) (9 grams of protien; milk protein; Fonterra Co-operative Group Ltd, Auckland, New Zealand) or an isoenergetic carbohydrate placebo $(\mathrm{CHO})$. The FMP was manufactured from spray dried skim milk powder, spray dried milk protein concentrate, and additional calcium, magnesium, zinc, and vitamin $C$. The macronutrient and essential amino acid

Table 1 Subject characteristics

\begin{tabular}{lcc}
\hline & Placebo $(n=10)$ & $9 \mathrm{~g} \mathrm{MPC}(n=10)$ \\
\hline Age (years) & $45.5 \pm 5.8$ & $48.6 \pm 4.6$ \\
Height $(\mathrm{cm})$ & $175.9 \pm 5.6$ & $179.5 \pm 6.1$ \\
Weight $(\mathrm{kg})$ & $79.3 \pm 9.1$ & $76.3 \pm 8.4$ \\
BMI $\left(\mathrm{kg} / \mathrm{m}^{2}\right)$ & $24.6 \pm 2.4$ & $24.4 \pm 2.8$ \\
$\%$ Body fat & $19.3 \pm 7.6$ & $18.2 \pm 5.7$ \\
HDL cholesterol $(\mathrm{mmol} / \mathrm{L})$ & $1.36 \pm 0.30$ & $1.52 \pm 0.59$ \\
LDL cholesterol $(\mathrm{mmol} / \mathrm{L})$ & $4.13 \pm 1.10$ & $3.37 \pm 0.98$ \\
Triglycerides $(\mathrm{mmol} / \mathrm{L})$ & $1.27 \pm 0.52$ & $1.24 \pm 0.55$ \\
HOMA-IR & $1.81 \pm 1.33$ & $1.18 \pm 0.34$ \\
Leg press $1 \mathrm{RM}(\mathrm{kg})$ & $89.9 \pm 20.3$ & $92.5 \pm 23.8$ \\
Leg extension $1 \mathrm{RM}(\mathrm{kg})$ & $46.9 \pm 11.2$ & $45.3 \pm 15.7$ \\
\hline
\end{tabular}

Body mass index (BMI), high-density lipoprotein (HDL), low-density lipoprotein (LDL), Homeostatic model assessment of insulin resistance (HOMA-IR), one repetition maximum (1RM). Data are shown as mean \pm SD 
composition are shown in Table 2. Powders were dissolved in $250 \mathrm{ml}$ of water. Total protein in the beverages was calculated as 6.38 multiplied by total nitrogen determined using the Kjeldahl method. Essential amino acid composition of the FMP was determined using highperformance liquid chromatography.

\section{Experimental design}

At least 3 days prior to their clinical visit participants were familiarized with the leg press and leg extension apparatus. One repetition maximum (1RM) for each exercise was estimated using the Brzycki [28] equation based on a repetition set where muscle failure was achieved in less than 6 repetitions. Participants also underwent a full body dual energy $x$-ray absorptiometry (DXA, Lunar Prodigy, GE, Waltham, MA, USA) scan to quantify lean, fat and total mass. The day prior to the study visit participants consumed a standard evening meal containing $670 \mathrm{kcal}(50 \% \mathrm{CHO}, 25 \%$ protein, $25 \%$ fat). All participants arrived at the laboratory in the fasted state. Upon arrival, a cannula was inserted into an antecubital vein, a pre-exercise baseline blood sample was collected and a saline drip was then maintained for the remainder of the trial to keep the cannula patent. A muscle biopsy was obtained from the vastus lateralis of a random leg (counterbalanced for dominance) with a bergstrom needle modified for manual suction, under local anaesthesia ( $1 \%$ lidocaine).

Participants then completed four sets of unilateral leg press and extension using the leg contralateral to the first biopsy. Each set was performed at $80 \%$ of the participant's estimated 1RM, 10 repetitions were completed for the first three sets and the last set of each exercise was completed to the point of momentary muscular

Table 2 Study beverage composition

\begin{tabular}{lll}
\hline & $\begin{array}{l}\text { Functional milk } \\
\text { product }\end{array}$ & $\begin{array}{l}\text { Carbohydrate } \\
\text { placebo }\end{array}$ \\
\hline Energy (kJ) & 504 & 491 \\
Carbohydrate (g) & 13.8 & 28.0 \\
Fat (g) & 3.2 & 0.6 \\
Protein (g) & 9.2 & 0.1 \\
Essential amino acids & 4.0 & - \\
(g) & & \\
Threonine (g) & 0.43 & - \\
Valine (g) & 0.53 & - \\
Isoleucine (g) & 0.46 & - \\
Leucine (g) & 0.87 & - \\
Phenylalanine (g) & 0.42 & - \\
Lysine(g) & 0.72 & - \\
Histidine (g) & 0.23 & - \\
Methionine (g) & 0.21 & - \\
\hline
\end{tabular}

failure. After the completion of the exercise, a post exercise $(0 \mathrm{~min})$ blood sample was collected and participants then consumed their assigned study beverage in full within three minutes. Blood samples were then obtained in ethylenediaminetetraacetic acid coated vacutainers at 30, 60, 90, 120, 180 and 240 min after the study beverage was consumed.

Bilateral muscle biopsies were obtained 90 and 240 min after the beverage was consumed. This study design allowed for the delineation effects of exercise and protein feeding alone (FED) and together (FED-EX).

\section{Plasma measurements}

Baseline blood biochemistry and the time course of plasma glucose levels were analysed using a Roche C311 autoanalyzer, (Roche, Mannheim, Germany) by enzymatic colorimetric assay. Plasma insulin concentrations were analysed using electrochemiluminescence immunoassay on Cobas e 411 (Roche, Mannheim, Germany). The homeostatic model assessment (HOMA) insulin resistance was calculated based as reported by Mathews et al. [29]. Plasma samples were deproteinised by tungstate precipitation and amino acid concentrations were measured using a fluorescent derivitisation utilising the reaction of amino nitrogen with 6-aminoquinolyl-Nhydroxysuccinimidyl carbonate and subsequent separation by ultra-high pressure liquid chromatography as previously described [30].

\section{Immunoblotting}

Protein extractions were conducted as per Mitchell et al [24]. Briefly, muscle biopsies (40-50 mg) were homogenised for $40 \mathrm{~s}$ at $20 \mathrm{~Hz}$ using a TissueLyser (Qiagen, Venlo, Netherlands) in RIPA buffer $(10 \mu \mathrm{L} / \mathrm{mg} 25 \mathrm{mM}$ Tris $0.5 \% \mathrm{v} / \mathrm{v}$ Triton X-100) and protease/phosphatase inhibitor cocktail (HaltTM Protease and Phosphatase Inhibitor Cocktail, Thermo Scientific, cat. 78442). Samples were then centrifuged at $4500 \mathrm{~g}$ for $10 \mathrm{~min}$ at $4{ }^{\circ} \mathrm{C}$. The supernatant was collected for western blot analysis. The total protein content was determined using a BCAprotein kit following the manufacturer's protocols (Thermo Fisher Scientific, Waltham, MA, USA). Aliquots of $20 \mu \mathrm{g}$ total protein were prepared, suspended in Laemmli buffer, boiled, and subjected to SDS-PAGE. Western blotting was performed as previously described [12] using sodium dodecyl sulphate-polyacrylamide gel electrophoresis then transferred to a polyvinyl fluoride membrane using the Trans-Blot Turbo ${ }^{\text {max }}$ Transfer System (Bio-Rad, Hong Kong, China). membranes were then blocked in 5\% BSA/Tris Buffer Saline/0.1\% Tween 20 (TBST) for $2 \mathrm{~h}(\mathrm{~h})$ at room temperature, followed by overnight incubation at $4{ }^{\circ} \mathrm{C}$ with gentle agitation with primary antibodies (1:1000) (p-P70S6K (Thr389) (Cell Signalling, 9206S), p-P70S6K (Thr421/Ser424) (Cell 
Signalling, 9204S), p-rps6 (Ser235/236) (Cell Signalling, 4865S), p-rps6 (Ser240/244) (Cell Signalling, 2215S), pERK1/2 (Thr202/Tyr204) (Cell Signalling, 4370S), pP90RSK (Ser380) (Cell Signalling, 11989S), LAT1 (Cell Signalling, 5347S), SNAT2 (Santa Cruz, 67081), CAT1 (Abcam, ab37588) and GAPDH (Abcam, ab9485)). The following morning the membranes were washed for 30 min with TBST and probed with HRP conjugated goat anti-rabbit or goat anti-mouse secondary antibodies (Jackson ImmunoResearch, West Grove, PA, USA) for $1 \mathrm{~h}$ at room temperature. Following $30 \mathrm{~min}$ further washing in TBST, antibody binding was visualized using ECL Select Western blotting detection reagent (Amersham, UK) and chemiluminescent signals were captured using a ChemiDoc ${ }^{\mathrm{m}}$ MP Imaging System (Bio-Rad, Hong Kong, China). Densitometry analysis of protein bands was performed using Image J software. Abundance of proteins of interest was normalized for protein loading by stripping and re-probing membranes for GAPDH.

\section{Real-time polymerase chain reaction}

Total RNA was extracted from $\sim 20 \mathrm{mg}$ of muscle tissue using the AllPrep DNA/RNA/miRNA Universal Kit (QIAGEN GmbH, Hilden, Germany) following the manufacturer's instructions. $1500 \mathrm{ng}$ of input RNA was used for cDNA synthesis using High-Capacity RNA-to-cDNA ${ }^{\text {"m }}$ kit (Life Technologies, Carlsbad, CA), messenger RNA (mRNA) were measured by Real-time polymerase chain reaction on a LightCycler 480 II (Roche Applied Science, Penzberg, Germany) using SYBR Green I Master Mix (Roche Applied Science). As per Figueiredo et al. [31] target mRNAs were LAT1/SLC7A5, PAT1/SLC36A1, CAT1/SLC7A1, and SNAT2/SLC38A2. Primers were designed using BLAST [32] software with sequences in Table 3. The geometric mean of five reference genes [33] was used for normalisation. The recently proposed human reference genes [34], ER membrane protein complex subunit 7 (EMC7), valosin-containing protein $(V C P)$, charged multivesicular body protein $2 \mathrm{~A}$ (CHMP2A), chromosome 1 open reading frame 43 (C1orf43) and hypoxanthine phosphoribosyltransferase 1 (HRPT) were identified as the least variable and therefore, used as reference genes (Table 4). Standard and melting curves were performed for every target to confirm primer efficiency and single-product amplification. Due to insufficient sample volumes, RNA data at $90 \mathrm{~min}$ post beverage consumption was not available.

\section{Statistical analysis}

Differences in protein phosphorylation and gene expression were tested using three-way ANOVA with time and exercise as repeated fixed factors and study beverage as a between subject fixed factor. Differences in plasma
Table 3 Primer sequences

\begin{tabular}{ll}
\hline LAT1 (Forward) & CATCCTCCAGGCTCTTCTTCGTG \\
LAT1 (Reverse) & AAGGCGTAGAGCAGCGTCAT \\
SNAT2 (Forward) & GCAGTGGAATCCTTGGGCTT \\
SNAT2 (Reverse) & AAAGACCCTCCTTCATTGGCAG \\
CAT1 (Forward) & TCTCATTTAAGGTCCCTTCCTG \\
CAT1 (Reverse) & ACAGGCCATAGCCAAAGTAGA \\
PAT1 (Forward) & CTTCTGCCGCAGGCTGAATAAA \\
PAT1 (Reverse) & CAGGAAGAAGTCCACAACACG \\
SESTRIN1 (Forward) & TTCGTGTCCAGGACTATTGC \\
SESTRIN1 (Reverse) & ACTGTCCCACATCTGGATAAAGG \\
SESTRIN2 (Forward) & CAACCTCTTCTGGAGGCACTT \\
SESTRIN2 (Reverse) & CCTGCTCAGGAGTCAGGTCA \\
SESTRIN3 (Forward) & CAGGCAGCAACTTTGGATTGT \\
SESTRIN3 (Reverse) & AGACGCCTCTTCATCTTCCCTT \\
\hline
\end{tabular}

parameters were tested with two-way ANOVA with time as a repeated fixed factor and study beverage as a between subject fixed factor. Sidak post hoc test was used when significant interactions were present. All analysis was conducted using SPSS version 23 (IBM, Armonk, New York, United States). Alpha was set at $P<0.05$ and data are shown as means \pm standard deviation (SD) in the tables and text and \pm standard error of the mean (SEM) in the figures.

\section{Results}

\section{Plasma}

As expected $\mathrm{CHO}$ ingestion increased both glucose (time $\mathrm{X}$ group $P<0.001$ ) and insulin (time $\mathrm{X}$ group $P=0.015$ ) concentrations above baseline and were greater than the concentrations observed for FMP 30 and $60 \mathrm{~min}$ after ingestion of the beverage $(P<0.05)$ (Fig. 1a\&b). Total amino acid concentrations (Fig. 2a) (time $\mathrm{X}$ group $P=0.016$ ) were elevated above baseline at 30, 60 and 90 min after the ingestion of $9 \mathrm{~g}$ of FMP $(P<0.05)$ but were not altered

Table 4 Primer sequences for housekeeping genes

\begin{tabular}{ll}
\hline Gene & Sequence \\
\hline EMC7 (Forward) & GGGCTGGACAGACTTTCTAATG \\
EMC7 (Reverse) & CTCCATTTCCCGTCTCATGTCAG \\
VCP (Forward) & AAACTCATGGCGAGGTGGAG \\
VCP (Reverse) & TGTCAAAGCGACCAAATCGC \\
CHMP2A (Forward) & CGCTATGTGCGCAAGTTGT \\
CHMP2A (Reverse) & GGGGCAACTTCAGCTGTCTG \\
C1orf43 (Forward) & CTATGGGACAGGGGTCTTTGG \\
C1orf43 (Reverse) & TTGGCTGCTGACTGGTGAT \\
HPRT (Forward) & CCTGGCGTCGTGATTAGTGAT \\
HPRT (Reverse) & TCGAGCAAGACGTTCAGTCC \\
\hline
\end{tabular}




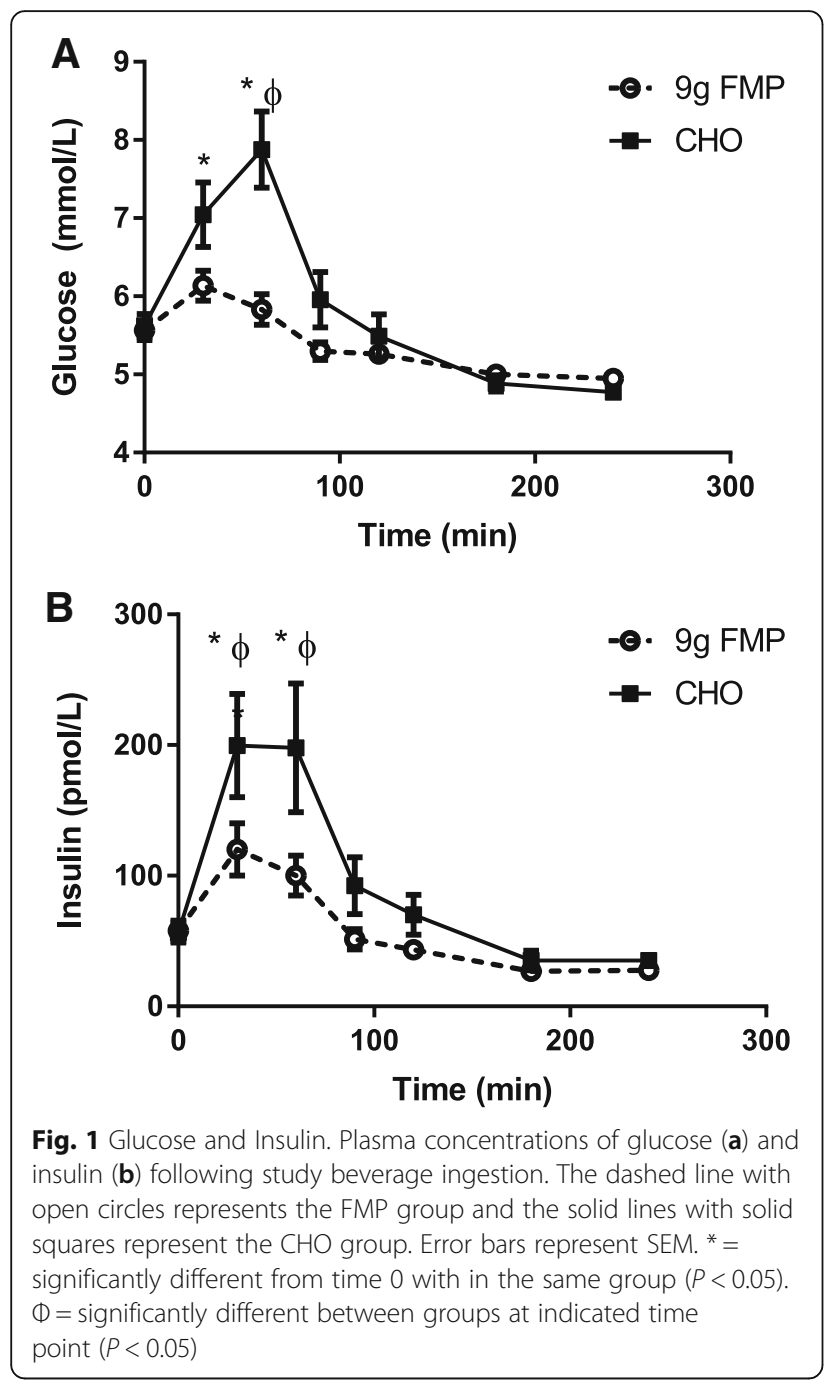

in the $\mathrm{CHO}$ group. There was also a difference between the two groups over this time period $(P<0.05)$. Non-essential amino acids (Fig. 2b) followed the same pattern (time $\mathrm{X}$ group $P=0.057$, group $P=0.012$, time $P<0.001)$ and were elevated only after FMP consumption at 30 and $90 \mathrm{~min}(P<0.05)$. There was also a difference between groups over this time period $(P<$ 0.05). Essential amino acid concentrations (Fig. 2c) (time $\mathrm{X}$ group $P=0.012$ ) were greater in the FMP group compared to the $\mathrm{CHO}$ group for the entire post beverage ingestion period $(P<0.05)$. Essential amino acid concentrations were depressed below baseline from $90 \mathrm{~min}$ post beverage ingestion for the remainder of the measurement period only in the $\mathrm{CHO}$ group. Branched chain amino acids (Fig. 2d) (time $\mathrm{X}$ group $P=0.010$ ) were depressed for the full measurement period after study beverage consumption only in the $\mathrm{CHO}$ group $(P<$ $0.05)$, there were also differences between groups for the full post beverage period $(P<0.05)$.

\section{Anabolic signalling}

Phosphorylation of P70S6K at the threonine 389 residue (leg $\mathrm{X}$ time $P=0.001$ ) increased with exercise $90 \mathrm{~min}$ after beverage consumption $(P=0.004)$. Phosphorylation of the FED-EX leg was also greater than the FED leg at 90 and 240 min post beverage consumption $(P<0.05)$. There was no difference between groups (group $\mathrm{X}$ time $P=0.830$ ) (Fig. 3a). P70S6K phosphorylation at the threonine 421 /serine424 site increased above baseline (leg $\mathrm{X}$ time $P=0.001$, group $\mathrm{X} \operatorname{leg} P=0.117$, time $\mathrm{X}$ leg $\mathrm{X}$ group $P=0.257$ ) in the exercise leg of both groups $90 \mathrm{~min}$ post beverage consumption (FMP $P=0.002$, CHO $P=0.022$ ), phosphorylation was greater in the exercise leg than the rest leg at this time point only in the FMP group $(P=0.004)$. At $240 \mathrm{~min}$ after beverage consumption, phosphorylation was increased only in the exercise leg of the FMP group $(P=0.005)$, and was greater in the exercise leg of the FMP group than the rest leg at the same time $(P=0.001)$ (Fig. $3 \mathrm{~b})$. rpS6 phosphorylation at the serine235/236 site increased in the exercise leg of both groups at both 90 and 240 min after beverage consumption (leg $\mathrm{X}$ time $P=0.010$, group $\mathrm{X}$ leg $P=0.177$, time $\mathrm{X}$ leg $\mathrm{X}$ group $P=0.256$ ), with greater phosphorylation observed in the exercise than the rest leg at $90 \mathrm{~min}$ in the $\mathrm{CHO}$ group $(P=0.049)$ and at $240 \mathrm{~min}$ in the FMP group $(P<0.001)$, and phosphorylation in the exercise leg at $240 \mathrm{~min}$ was greater following FMP than CHO $(P=0.048)$ (Fig. 3c). Phosphorylation of rpS6 at the serine240/244 site (leg $X$ time $P=0.001$, group $X$ leg $P=0.007$, time $\mathrm{X}$ leg $\mathrm{X}$ group $P=0.076$ ), increased above baseline with exercise in the FMP group at both 90 and 240 min after beverage consumption $(P<0.001)$ and was greater than in the resting leg $(P=0.010)$. rpS6 phosphorylation was greater in the exercise leg of the FMP group compare to the $\mathrm{CHO}$ group at $240 \mathrm{~min}$ post beverage consumption $(P=0.022)$ (Fig. 3d). Phosphorylation of ERK1/2, (leg $P=0.041$, leg $X$ time $P=0.061$ ) was increased with exercise regardless of time point and with no difference between groups (Fig. 3d). p90RSK phosphorylation at serine380 (leg $\mathrm{X}$ time $P=0.034$ ) was increased with exercise at $240 \mathrm{~min}$ post beverage consumption $(P=0.006)$ when compared to the FED only leg (Fig. 3e).

\section{Amino acid transporters}

mRNA expression of LAT1/ SLC7A5 increased $240 \mathrm{~min}$ after study beverage ingestion $(P<0.001)$ regardless of exercise or the beverage consumed (Fig. 4a). PAT1/ SLC36A1 (time X leg $P=0.027$ ), CAT1/ SLC7A1 (time X leg $P=0.029$ ), and SNAT2/ SLC38A2mRNA (time X leg $P<0.001$ ), expression increased $240 \mathrm{~min}$ after beverage consumption only in the exercise leg and was greater than expression in the FED only leg (Fig. 4b, c \& d). 
A
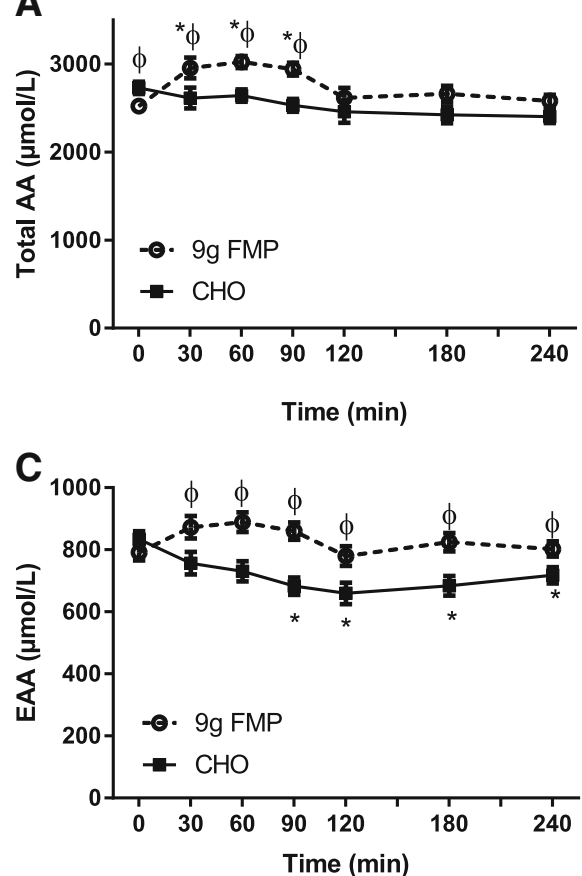

B
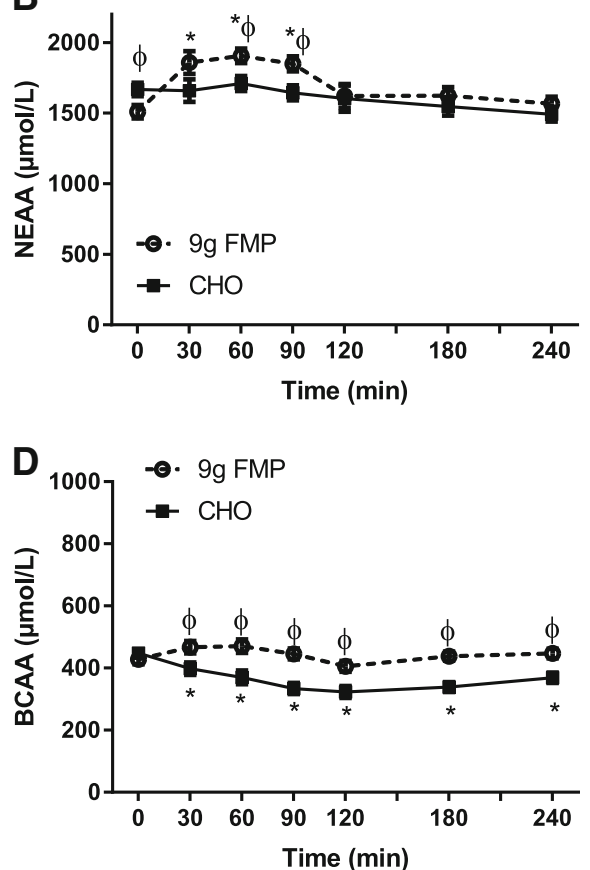

Fig. 2 Amino acids. Plasma concentrations of amino acids (AA) (a), non-essential amino acids (NEAA) (b), essential amino acids (EAA) (c), and branched chain amino acids (BCAA) (d) following study beverage ingestion. The dashed line with open circles represent the FMP group and the solid lines with solid squares represent the $\mathrm{CHO}$ group. Error bars represent SEM. ${ }^{*}=$ significantly different from time 0 with in the same group $(P<0.05)$. $\Phi=$ significantly different between groups at indicated time point $(P<0.05)$
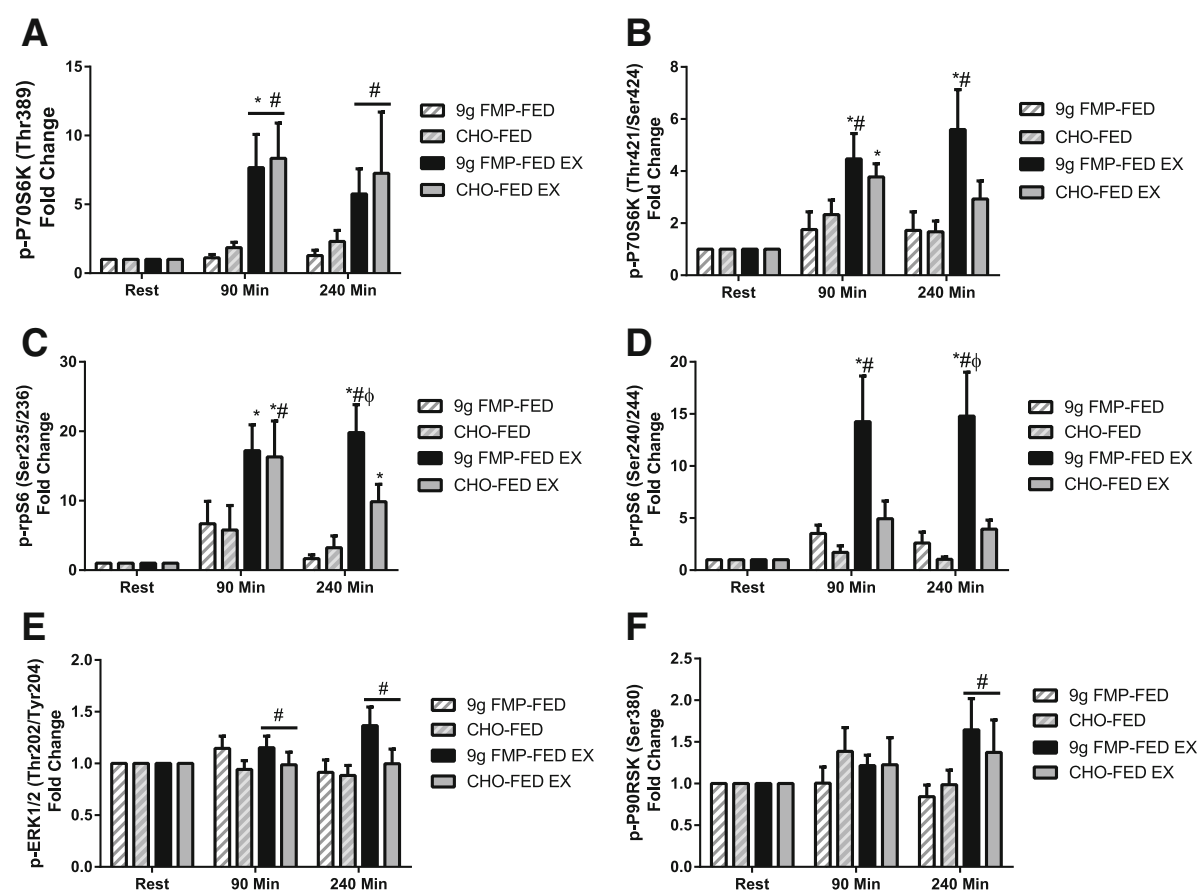

Fig. 3 Anabolic signalling. Fold changes in phosphorylation status of P70S6K ${ }^{\text {Thr389 }}$ (a), P70S6K ${ }^{\text {Thr } 421 / \operatorname{Ser} 42} 4$ (b), rpS6 ${ }^{\text {Ser235/236 }}$ (c), rpS6 ${ }^{\text {Ser240/244 }}$ (d), ERK1/2 Thr202/Tyr204 (e) and P90RSK ${ }^{\text {Ser360 }}(\mathbf{f})$ after feeding both at rest and following resistance exercise. Error bars represent SEM, horizontal line represent a main effect. \# = significantly different from FED only leg at same time point $(P<0.05)$. $\Phi=$ significantly different between groups at indicated time point, within the exercise condition $(P<0.05) .{ }^{*}=$ significantly different from rested baseline samples $(P<0.05)$ 


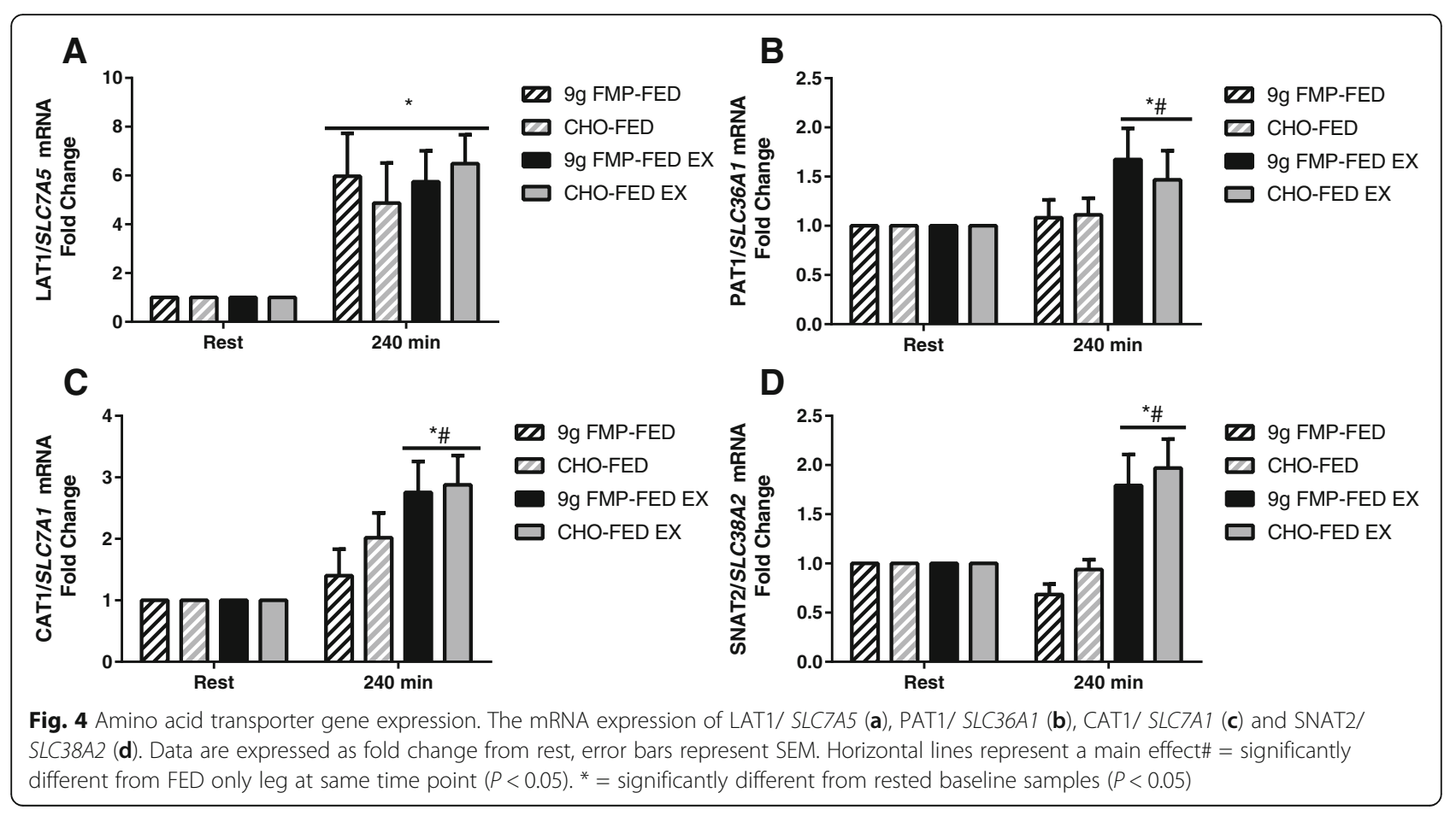

Protein expression of LAT1 and CAT1 was unaltered by beverage consumption or exercise (Fig. 5a\&b). SNAT2 protein expression (time $\mathrm{X}$ leg $\mathrm{X}$ group $P=$ 0.021 ) was increased 240 min after beverage consumption only in the exercise leg of the FMP group $(P=$ 0.026) and was greater than the FED only leg at the same time point $(P=0.005)$ (Fig. $5 \mathrm{c})$. Representative images of western blots are shown in Fig. 6.

\section{Discussion}

Resistance exercise is a potent stimulator of muscle hypertrophy [35], MPS [36] and downstream mTORC1 signalling [12]. Protein feeding acts synergistically with resistance exercise to augment the signalling and MPS response observed with resistance training alone [12, 37]. Although less clear for muscle hypertrophy, the dose of protein required to maximally stimulate MPS and anabolic signalling after resistance exercise has been established and is known to increase with age [38]. The present study established that in middle-aged males ( $46.3 \pm 5.7$ years) 9 grams of milk protein augments the signalling response to resistance exercise. Yet this dose of protein did not impact gene expression of major skeletal muscle amino acid transporters when consumed immediately post exercise. Therefore, the augmentation of post exercise mTORC1 signalling by 9 grams of milk protein is likely to enhance muscle anabolism even though the magnitude of this potential effect is difficult to quantify based on the current data.
The two beverages used in the present study differed in protein content but were isoenergetic, with the balance being made up by $\mathrm{CHO}$. The $\mathrm{CHO}$ placebo stimulated a much larger insulin and glucose response when compared to the protein beverage. Although, the greater insulin response provoked by the $\mathrm{CHO}$ may have stimulated signalling upstream of mTORC1, consistent with previous studies, insulin alone was insufficient to stimulate downstream signalling or MPS [25, 39].

Both total and non-essential amino acid concentrations were unaltered by $\mathrm{CHO}$ ingestion combined with unilateral resistance exercise, whilst the ingestion of 9 grams of FMP resulted in a transient increase in these concentrations. Conversely, essential and branched chain amino acid concentrations were depressed by $\mathrm{CHO}$ ingestion combined with unilateral exercise whereas ingestion of the FMP maintained essential and branched chain amino acid concentrations for the duration of the study period. A small suppression of plasma essential amino acid concentrations following resistance exercise in the fasted state has previously been reported [37, 40] and may be the result of increased catabolism of branched chain amino acids [41]. It is not clear if the observed suppression of essential amino acids is the result of increased uptake promoted by the exercise or due to insulin which was secreted in response to the $\mathrm{CHO}$ placebo. Based on classic work by Biolo et al. [42] it appears unlikely that the decreased plasma essential amino acid concentration was the result of uptake by the exercised muscle and therefore would not have been beneficial for 


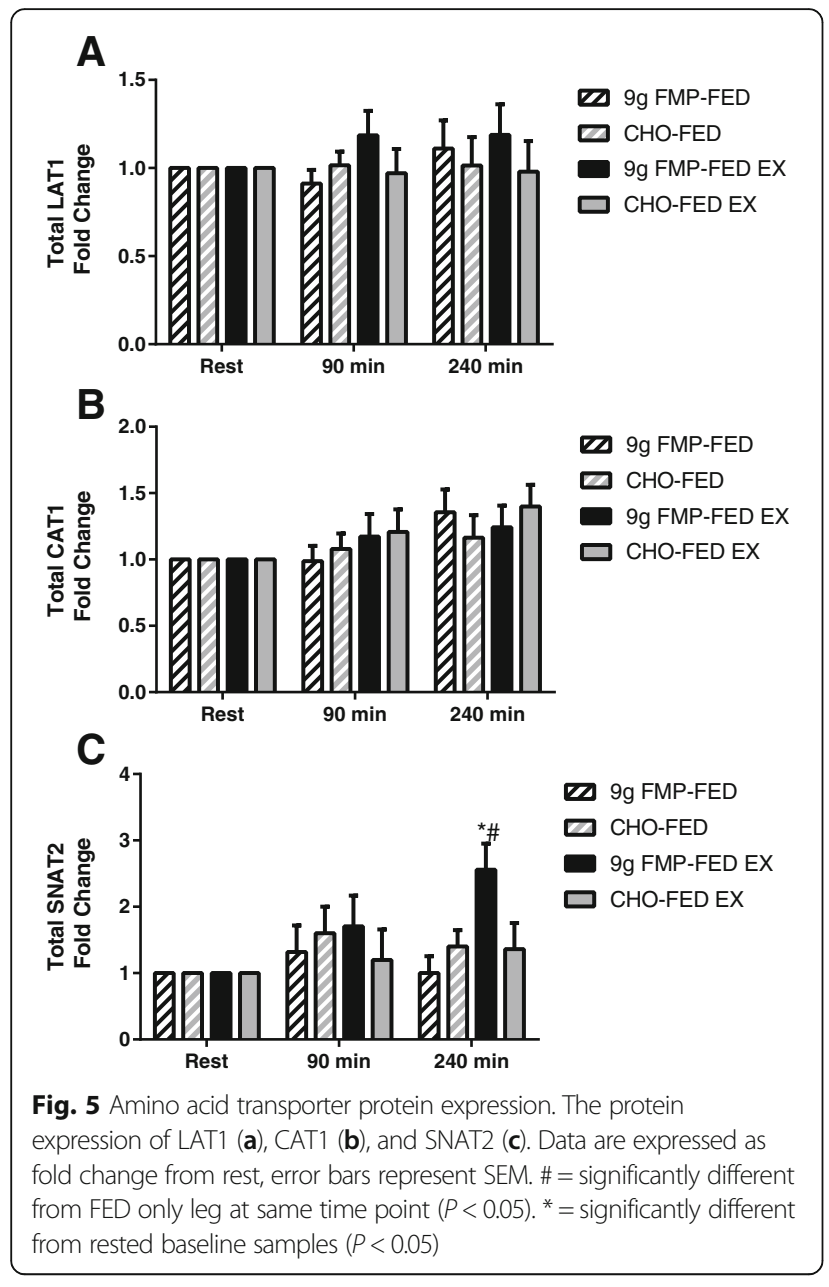

anabolism. It is likely that the maintained concentrations of essential and branched chain amino acids in the FMP group would sustain amino acid availability to muscle tissue to support anabolism.

Signalling via the mTORC1 pathway is required for MPS to be increased following resistance exercise [19], mTOR exists in a complex with a number of other proteins and its activity is normally measured by the phosphorylation status of its downstream targets [20]. We show that in agreement with previous studies [12, 21, 43] $\mathrm{p} 70 \mathrm{~S} 6 \mathrm{~K}^{\mathrm{Thr} 389}$ is activated following resistance exercise at both 90 and 240 min after exercise. The phosphorylation of p $70 \mathrm{~S} 6 \mathrm{~K}^{\mathrm{Thr} 389}$ has previously been shown to be sensitive to higher dose protein feeding both at rest and after exercise [43]. Our results suggest that perhaps a larger protein dose would be required to further increase phosphorylation above exercise alone or that an earlier time point may have been required to observe a synergistic protein feeding effect [12]. Although the p70S6K $\mathrm{K}^{\mathrm{Thr} 421 / \mathrm{Ser} 424}$ phosphorylation site has been measured less frequently than the p70S6 $\mathrm{K}^{\text {Thr389 }}$ site it has been shown to be sensitive to muscle resistance exercise and amino acid intake [44]. While the present study shows that phosphorylation at the p70S6K ${ }^{\text {Thr421/Ser424 }}$ site is increased by resistance exercise at $90 \mathrm{~min}$ post exercise, this response is only sustained at $240 \mathrm{~min}$ following the consumption of FMP. $\mathrm{rpS6}^{\mathrm{Ser} 235 / 236}$ phosphorylation was increased by exercise but maintained at a higher magnitude in the FMP compared to the $\mathrm{CHO}$ group. Glover and colleagues report that $\mathrm{rpS6}^{\mathrm{Ser} 235 / 236}$ phosphorylation was increased by both exercise and a similar dose of protein to the present study but that these increases were not additive [45]. The $\mathrm{rpS6}^{\mathrm{Ser} 240 / 244}$ site was only phosphorylated by the combination of exercise and protein intake. This site is known to be sensitive to protein intake after resistance exercise [45] but has not previously been tested with the dose of protein or protein source used in the present study. The mitogen-activated protein kinase (MAPK) pathway is also known to converge with mTORC1 signalling to regulate the initiation of protein translation [44]. The MAPK targets ERK1/2 and p90RSK were activated following resistance exercise with protein intake having no effect. Previously it has been shown that the MAPK pathway is primarily sensitive to cellular stress such as that caused by resistance exercise but not responsive to protein feeding [43].

Changes in amino acid transporters were assessed at the level of mRNA and protein expression. In agreement with previous studies, transcriptional changes were more robust than those observed for protein expression [26]. LAT1/ SLC7A5 gene expression was increased in all conditions at $240 \mathrm{~min}$ following beverage consumption. Based on the low concentrations of circulating essential amino acids during both the overnight fast and the study period it is possible that LAT1/SLC7A5 transcription was increased as a compensatory mechanism in all conditions [46]. The expression of CAT1/SLC7A1, PAT1/ SLC36A1, and SNAT2/SLC38A2 mRNA was increased by resistance exercise and unaffected by beverage consumption. This finding is in agreement with work by Drummond et al. [26] that showed resistance exercise mediated increase in amino acid transporter gene expression in both young and older adults, even though, the peak gene expression may have been after the end of the measurement period. Ten grams of essential amino acids have been shown to increase amino acid transporter expression at rest [27], the dose of protein used in the present study equates to $\sim 4.0$ grams of essential amino acids. It seems that a dose of essential amino acids larger than the 4.0 grams used in the present study may be required to stimulate amino acid transporter transcription. A synergism between resistance exercise and protein intake for amino acid transporter transcription has never been clearly demonstrated, thus it is unclear if the ingestion of a greater protein dose would 


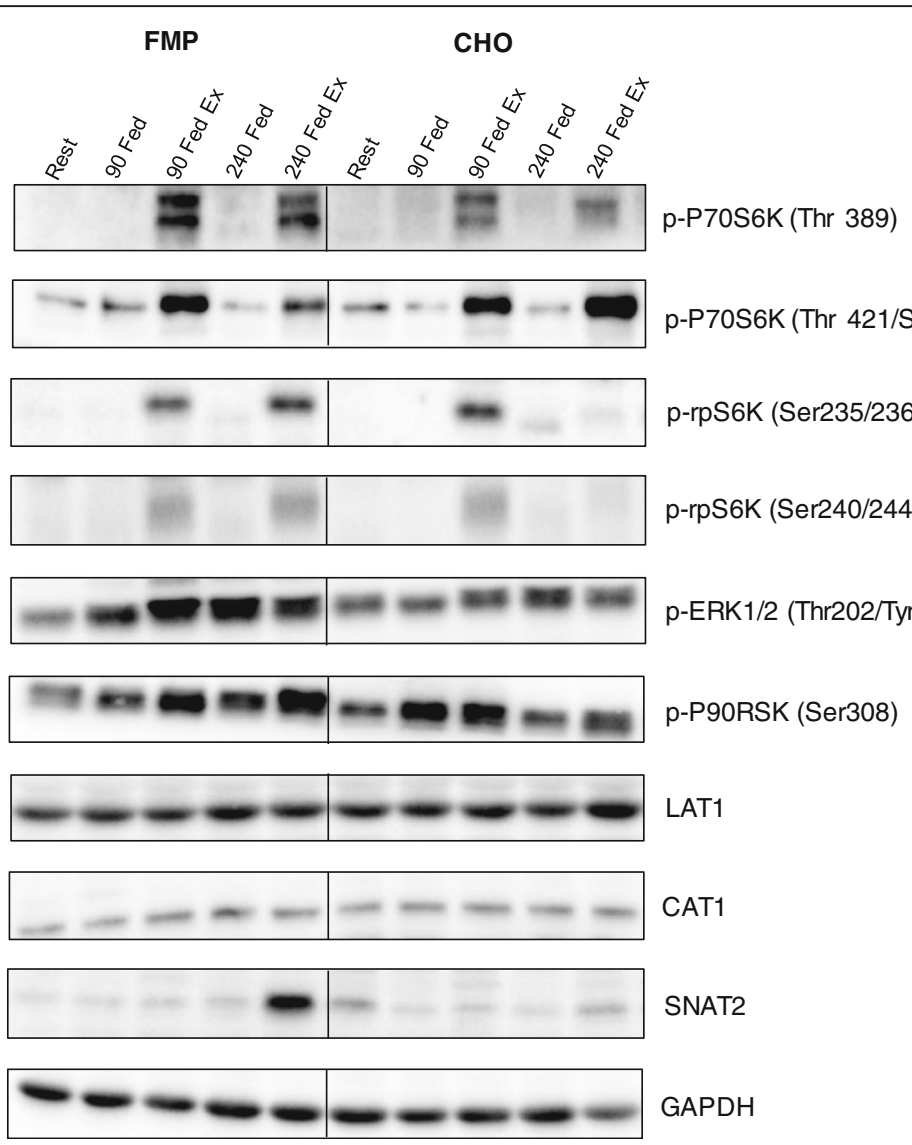

Fig. 6 Representative images of western blots for data shown in Figs. 3 and 5

have further increased amino acid transporter gene expression after resistance exercise.

The participants in the present study were middle aged. This is unique as most studies that measure muscle anabolism after exercise and feeding investigate either young adults or older adults. For this reason much less is known about the dose response of anabolic signalling to exercise and protein feeding in middle age. It seems reasonable to surmise that the anabolic sensitivity of middle aged men would be intermediate between the high sensitivity of young men [47] and the diminished sensitivity of older men $[11,12]$. It is clear that 9 grams of milk protein represents a suboptimal stimulus to promote mTORC1 signalling after resistance exercise. However despite that finding, a product containing 9 to 10 grams of protein could still make the content claim 'good source of protein' in many parts of the world $[48,49]$. This level of protein intake has been shown to have a detectable anabolic benefit in young men $[40,45]$ and we extend these findings by showing an anabolic benefit after resistance exercise in middle aged men. The present study was limited by the relatively small sample size and the lack of female participants. Future work should test the effects of small protein does in a larger cohort of both men and women.

\section{Conclusions}

As little as $9 \mathrm{~g}$ of high quality milk protein is able to augment the downstream signalling response induced by resistance exercise in middle aged men but does not potentiate the increase in amino acid transporter gene expression after resistance exercise. Therefore, formulated products containing 9 grams of milk protein would be expected to exert a stimulatory effect on muscle anabolism after resistance exercise. This may be of benefit in the development of food products targeted towards population groups that are unable to tolerate single dose high-protein products or that are unfamiliar with the tastes and sensory properties of high-protein supplemental foods and beverages.

\section{Abbreviations}

1RM: One rep maximum; CHO: Carbohydrate; DXA: Dual-energy X-ray absorptiometry; FED: Leg that was exposed nutrition but remained rested; FED-

EX: Leg which was exposed to both nutrition and resistance exercise; FMP: Functional milk product; HOMA: Homeostatic model assessment of insulin resistance; MPC: Milk protein concentrate; MPS: Muscle protein synthesis; mTORC1: Mammalian target of rapamycin complex 1;

P70S6K: P70S6 kinase; rpS6: Ribosomal protein S6; TBST: Tris buffered saline and tween 20

Acknowledgments Not applicable 


\section{Funding}

Funding for this study was provided by the New Zealand Primary Growth Partnership (PGP) post-farm gate programme, funded by Fonterra Cooperative Group Ltd and the NZ Ministry for Primary Industries (MPI). The sponsor of the study was not involved in the conduct of the study or the interpretation of the findings.

\section{Availability of data and materials}

Data and/or statistical analyses are available upon request to the corresponding author on a case by case basis for non-commercial scientific inquiry and/or educational use as long as ethics committee restrictions and research agreement terms are not violated.

\section{Authors' contributions}

CJM, DCS, SDP and ACF designed the study. CJM, SMM, and RFD conducted the experiment. CJM, RFD, NZ and KA analyzed the result. CJM wrote the manuscript. All authors critically revised and approved the final manuscript. CJM is responsible for the final content of the manuscript.

\section{Competing interests}

CJM, RDF and DCS received financial support from the New Zealand Primary Growth Partnership (PGP) post-farm gate programme, funded by Fonterra Co-operative Group Ltd and the NZ Ministry for Primary Industries (MPI). SDP is the Fonterra Chair in Human Nutrition, University of Auckland; ACF is a current employee of Fonterra Co-operative Group Ltd.

\section{Consent for publication}

This section is not applicable as our manuscript does not contain any individual or identifying data.

\section{Ethics approval and consent to participate}

All participants provided informed verbal and written consent, the study was approved by the Health and Disability Ethics Committee (New Zealand, Ref\# 15/NTB/154/AM01) and registered with the Australia New Zealand Clinical Trials Registry ACTRN12615001375549.

\section{Publisher's Note}

springer Nature remains neutral with regard to jurisdictional claims in published maps and institutional affiliations.

\section{Author details}

'Liggins Institute, The University of Auckland, Private Bag 92 019, Victoria Street West, Auckland 1142, New Zealand. ${ }^{2}$ School of Biological Sciences, The University of Auckland, Private Bag 92 019, Victoria Street West, Auckland 1142, New Zealand. ${ }^{3}$ Fonterra Research and Development Centre, Private Bag 11 029, Palmerston North 4442, New Zealand.

\section{Received: 12 February 2017 Accepted: 30 May 2017}

Published online: 08 June 2017

\section{References}

1. Srikanthan P, Karlamangla AS. Relative muscle mass is inversely associated with insulin resistance and prediabetes. Findings from the third national health and nutrition examination survey. J Clin Endocrinol Metab. 2011;96: 2898-903.

2. Newman $A B$, Haggerty $C L$, Goodpaster B, et al. Strength and muscle quality in a well-functioning cohort of older adults: The health, aging and body composition study. J Am Geriatr Soc. 2003;51:323-30.

3. McGregor RA, Cameron-Smith D, Poppitt SD. It is not just muscle mass: A review of muscle quality, composition and metabolism during ageing as determinants of muscle function and mobility in later life. Longev Healthspan. 2014:3:9.

4. Visser M, Goodpaster BH, Kritchevsky SB, et al. Muscle mass, muscle strength, and muscle fat infiltration as predictors of incident mobility limitations in well-functioning older persons. J Gerontol A Biol Sci Med Sci. 2005:60:324-33.

5. Janssen I, Heymsfield SB, Wang ZM, et al. Skeletal muscle mass and distribution in 468 men and women aged 18-88 yr. J Appl Physiol (1985). 2000;89:81-8
6. Brook MS, Wilkinson DJ, Phillips BE, et al. Skeletal muscle homeostasis and plasticity in youth and ageing: Impact of nutrition and exercise. Acta Physiol (Oxf). 2016;216:15-41.

7. Mitchell CJ, Oikawa SY, Ogborn DI, et al. Daily chocolate milk consumption does not enhance the effect of resistance training in young and old men: A randomized controlled trial. Appl Physiol Nutr Metab. 2015;40:199-202.

8. Welle S, Totterman S, Thornton C. Effect of age on muscle hypertrophy induced by resistance training. J Gerontol A Biol Sci Med Sci. 1996;51:M270-5.

9. Kosek DJ, Kim JS, Petrella JK, et al. Efficacy of 3 days/wK resistance training on myofiber hypertrophy and myogenic mechanisms in young vs. Older adults. J Appl Physiol (1985). 2006;101:531-44

10. Cermak NM, Res PT, de Groot LC, et al. Protein supplementation augments the adaptive response of skeletal muscle to resistance-type exercise training: A meta-analysis. Am J Clin Nutr. 2012;96:1454-64.

11. Yang $Y$, Breen $L$, Burd NA, et al. Resistance exercise enhances myofibrillar protein synthesis with graded intakes of whey protein in older men. $\mathrm{Br}$ J Nutr. 2012:108:1780-8.

12. D'Souza RF, Marworth JF, Figueiredo VC, et al. Dose-dependent increases in p70s6k phosphorylation and intramuscular branchedchain amino acids in older men following resistance exercise and protein intake. Physiol Rep. 2014;2(8). doi:10.14814/phy2.12112.

13. Drake M, Miracle R, Wright J. Sensory properties of dairy proteins. In: Milk proteins: From expression to food. Amsterdam: Elsevier; 2009. p. 429-48.

14. Çakır-Fuller E. Enhanced heat stability of high protein emulsion systems provided by microparticulated whey proteins. Food Hydrocoll. 2015:47:41-50.

15. Kumar V, Atherton P, Smith K, et al. Human muscle protein synthesis and breakdown during and after exercise. J Appl Physiol. 2009;106:2026-39.

16. Glynn EL, Fry CS, Drummond MJ, et al. Muscle protein breakdown has a minor role in the protein anabolic response to essential amino acid and carbohydrate intake following resistance exercise. Am J Physiol Regul Integr Comp Physiol. 2010;299:R533-40

17. Damas F, Phillips SM, Libardi CA, et al. Resistance training-induced changes in integrated myofibrillar protein synthesis are related to hypertrophy only after attenuation of muscle damage. J Physiol. 2016; 594:5209-22.

18. Mitchell CJ, Churchward-Venne TA, Cameron-Smith D, et al:: What is the relationship between the acute muscle protein synthetic response and changes in muscle mass? J Appl Physiol (1985). 2015;118(4):495-7.

19. Drummond MJ, Fry CS, Glynn EL, et al. Rapamycin administration in humans blocks the contraction-induced increase in skeletal muscle protein synthesis. J Physiol. 2009:587:1535-46.

20. Drummond MJ, Dreyer HC, Fry CS, et al. Nutritional and contractile regulation of human skeletal muscle protein synthesis and mtorc1 signaling. J Appl Physiol. 2009;106:1374-84

21. Kumar V, Selby A, Rankin D, et al. Age-related differences in the doseresponse relationship of muscle protein synthesis to resistance exercise in young and old men. J Physiol. 2009:587:211-7.

22. Mitchell Cl, Churchward-Venne TA, Bellamy L, et al. Muscular and systemic correlates of resistance training-induced muscle hypertrophy. PLoS One. 2013;8:e78636.

23. Terzis G, Georgiadis G, Stratakos G, et al. Resistance exercise-induced increase in muscle mass correlates with p70s6 kinase phosphorylation in human subjects. Eur J Appl Physiol. 2008;102:145-52.

24. Mitchell CJ, McGregor RA, D'Souza RF, et al. Consumption of milk protein or whey protein results in a similar increase in muscle protein synthesis in middle aged men. Nutrients. 2015;7:8685-99.

25. Mitchell CJ, D'Souza RF, Zeng N, et al. Understanding the sensitivity of muscle protein synthesis to dairy protein in middle-aged men. Int Dairy J. 2016;63:35-41.

26. Drummond MJ, Fry CS, Glynn EL, et al. Skeletal muscle amino acid transporter expression is increased in young and older adults following resistance exercise. J Appl Physiol (1985). 2011;111:135-42.

27. Drummond MJ, Glynn EL, Fry CS, et al. An increase in essential amino acid availability upregulates amino acid transporter expression in human skeletal muscle. Am J Physiol Endocrinol Metab. 2010;298:E1011-8.

28. Brzycki M: A practical approach to strength training: Blue River Press; 2012 (Series Editor)

29. Matthews DR, Hosker JP, Rudenski AS, et al. Homeostasis model assessment: Insulin resistance and beta-cell function from fasting plasma glucose and insulin concentrations in man. Diabetologia. 1985:28:412-9.

30. Milan AM, D'Souza RF, Pundir S, et al. Older adults have delayed amino acid absorption after a high protein mixed breakfast meal. J Nutr Health Aging. 2015;19:839-45. 
31. Figueiredo VC, Roberts LA, Markworth JF, et al. Impact of resistance exercise on ribosome biogenesis is acutely regulated by post-exercise recovery strategies. Physiol Rep. 2016;4(2). doi:10.14814/phy2.12670.

32. Ye J, Coulouris G, Zaretskaya I, et al. Primer-blast: A tool to design target-specific primers for polymerase chain reaction. BMC Bioinformatics. 2012;13:134.

33. Vandesompele J, De Preter K, Pattyn F, et al.: Accurate normalization of realtime quantitative rt-pcr data by geometric averaging of multiple internal control genes. Genome Biol 2002, 3:RESEARCH0034.

34. Eisenberg E, Levanon EY. Human housekeeping genes, revisited. Trends Genet. 2013;29:569-74.

35. Hubal MJ, Gordish-Dressman $\mathrm{H}$, Thompson PD, et al. Variability in muscle size and strength gain after unilateral resistance training. Med Sci Sports Exerc. 2005;37:964-72.

36. Mitchell CJ, Churchward-Venne TA, Parise G, et al. Acute post-exercise myofibrillar protein synthesis is not correlated with resistance traininginduced muscle hypertrophy in young men. PLoS One. 2014;9:e89431.

37. Witard OC, Jackman SR, Breen L, et al. Myofibrillar muscle protein synthesis rates subsequent to a meal in response to increasing doses of whey protein at rest and after resistance exercise. Am J Clin Nutr. 2014;99:86-95.

38. Moore DR, Churchward-Venne TA, Witard O, et al. Protein ingestion to stimulate myofibrillar protein synthesis requires greater relative protein intakes in healthy older versus younger men. J Gerontol A Biol Sci Med Sci. 2015;70:57-62.

39. Staples AW, Burd NA, West DW, et al. Carbohydrate does not augment exercise-induced protein accretion versus protein alone. Med Sci Sports Exerc. 2011:43:1154-61.

40. Tang JE, Manolakos JJ, Kujbida GW, et al. Minimal whey protein with carbohydrate stimulates muscle protein synthesis following resistance exercise in trained young men. Appl Physiol Nutr Metab. 2007;32:1132-8.

41. Shimomura Y, Murakami T, Nakai N, et al. Exercise promotes bcaa catabolism: Effects of bcaa supplementation on skeletal muscle during exercise. J Nutr. 2004;134:1583S-7S.

42. Biolo G, Williams BD, Fleming RY, et al. Insulin action on muscle protein kinetics and amino acid transport during recovery after resistance exercise. Diabetes. 1999;48:949-57.

43. Moore DR, Atherton PJ, Rennie MJ, et al. Resistance exercise enhances mtor and mapk signalling in human muscle over that seen at rest after bolus protein ingestion. Acta Physiol (Oxf). 2011;201:365-72.

44. Karlsson HK, Nilsson PA, Nilsson J, et al. Branched-chain amino acids increase p70s6k phosphorylation in human skeletal muscle after resistance exercise. Am J Physiol Endocrinol Metab. 2004;287:E1-7.

45. Glover El, Oates BR, Tang JE, et al. Resistance exercise decreases eif2bepsilon phosphorylation and potentiates the feeding-induced stimulation of p70s6k1 and rps6 in young men. Am J Physiol Regul Integr Comp Physiol. 2008;295:R604-10.

46. Chen R, Zou Y, Mao D, et al. The general amino acid control pathway regulates mtor and autophagy during serum/glutamine starvation. J Cell Biol. 2014;206:173-82.

47. Moore DR, Robinson MJ, Fry JL, et al. Ingested protein dose response of muscle and albumin protein synthesis after resistance exercise in young men. Am J Clin Nutr. 2009;89:161-8.

48. Guidance for industry: A food labeling guide, Office of Nutrition L, and Dietary Supplements Editor. 2013, Food and Drug Administration College Park, MD

49. FSANZ. Food Standards Code. Food Standards Australia New Zealand. 2016. http://www.foodstandards.govt.nz/code/Pages/default.aspx. Accessed 20 Nov 2016.

\section{Submit your next manuscript to BioMed Central and we will help you at every step:}

- We accept pre-submission inquiries

- Our selector tool helps you to find the most relevant journal

- We provide round the clock customer support

- Convenient online submission

- Thorough peer review

- Inclusion in PubMed and all major indexing services

- Maximum visibility for your research

Submit your manuscript at www.biomedcentral.com/submit
Biomed Central 